\title{
Fatigue Life Prediction of Half-Shaft Using the Strain-Life Method
}

\author{
Xipei Ma, Xintian Liu $(\mathbb{D}$, Haijie Wang, Jiachi Tong, and Xiaobing Yang \\ School of Mechanical and Automotive Engineering, Shanghai University of Engineering Science, Shanghai, China \\ Correspondence should be addressed to Xintian Liu; xintianster@gmail.com
}

Received 19 April 2020; Revised 3 July 2020; Accepted 8 July 2020; Published 5 August 2020

Guest Editor: Guian Qian

Copyright (c) 2020 Xipei Ma et al. This is an open access article distributed under the Creative Commons Attribution License, which permits unrestricted use, distribution, and reproduction in any medium, provided the original work is properly cited.

Fatigue life prediction is an important part of the reliability and durability analysis of automobile components. Based on Wang and Brown's framework, multiaxial random fatigue damage was adopted to predict the fatigue life of half-shaft. The stress analysis of half-shaft was resolved analytically to determine the local stress tensor in the potential area of fracture. The maximum shear strain fatigue damage parameter and the normal stress fatigue damage parameter were evaluated to predict the fatigue life of halfshaft. The results show that the prediction method is reliable and meets the service life and safety requirements.

\section{Introduction}

In many engineering fields, the structures and components will crack and be fractured due to the accumulation of fatigue damage [1-3]. Therefore, fatigue has been widely studied [4-6]. As one of the key transmission parts, the fatigue durability of half-shaft has already been widely studied. However, bending or torsion loads are often treated separately $[7,8]$. And most of these studies on half-shaft are based on uniaxial fatigue theory [9-11].

The theory of fatigue life under the uniaxial load is actively investigated by many researchers for decades, and it is well-accepted for its simplicity. A well-established workflow of 3 independent components has been set up for processing random load history. The components are the fatigue damage parameter, the rainflow cycle counting, and the accumulative rule [12]. The fatigue characteristics of the material specimen could be tested and examined through standard procedure $[13,14]$. However, in most engineering practices, the conventional workflow which is designated for the uniaxial load could not handle multiaxial random loads, which are inevitable in most application.

The dilemma faced of research on multiaxial random loads is far more complex than its counterpart in uniaxial fatigue. The most important reason is that the substep worked well in uniaxial application is no longer independent and coupled with each other as the rainflow requires uniaxial input and produces 2-dimensionmal result which only provides mean and amplitude of load [15]. To overcome the limitation in using conventional tools in fatigue life prediction under the multiaxial load, Bannantine and Socle proposed to use the rainflow method to either count the normal strain or the shear strain individually on the critical plane [16]. The critical plane is where the actual crack and fracture initiate and propagate [17-19]. Wang and Brown suggested using von Mises strain as the indicator for rainflow counting, and the time series need further manipulation before rainflow count [20]. Their approach has been tested and validated by several researchers, compared to the fatigue life under the proportional or nonproportional load with a constant path pattern $[21,22]$. Other attempts are, for instance, the application of energy-based fatigue damage parameter $[8,23,24]$ or path-independent one [25].

However, the fatigue behavior of components under the multiaxial load in working condition remains uninvestigated since the sampled loads are too complex to be applied directly into the cycle-counting method. The load spectrum is one of the most efficient methods for processing raw load data in order to conduct the fatigue life test and analyze the fatigue life of components under working condition [26-28]. According to the collected random load, the load spectrum could be compiled and its characteristics could be extracted from the original signal [29-32]. 
In this paper, the fatigue life of half-shaft under both 3dimensional random nonproportional forces and moments was analyzed based on the accumulative multiaxial fatigue damage. The paper is organized as follows. In Section 2, the two-dimensional load spectrum was compiled according to the collected random load for the fatigue life benchmark test. In Section 3, the local stress tensor under external forces was determined by the resultant of torsion, bending, and tensile. In Section 4, Wang and Brown's method was applied to generate the load event from load history and calculate the fatigue damage for each load event. In Section 5, fatigue life of half-shaft was predicted with the linear fatigue damage accumulative rule. Finally, in Section 6, the conclusions were summarized.

\section{Compilation of Load Spectrum}

Before predicting the fatigue life, collecting the road load and compiling the load spectrum are the basis for the bench test. As shown in Figure 1, a set of load-time histories of left-front wheel collected by the six-component measuring system are introduced. The road load collection test was carried out on the strengthened pavement of proving ground according to the reliability endurance test standard. The test sampling frequency is $512 \mathrm{~Hz}$. The high-frequency load input could be recorded during the vehicle operating, which is essential to the validity of fatigue life prediction. The six components collected include the longitudinal force $F_{x}$, lateral force $F_{y}$, vertical force $F_{z}$, overturning torque $T_{x}$, driving torque $T_{y}$, and self-aligning torque $T_{z}$. The load-time history is shown in Figure 2.

Generally, the compilation of the load spectrum should be carried out according to certain operation process. The peak and valley values are firstly extracted from the collected random load. Then, by comparing the four adjacent peak and valley values, the rainflow counting method is used to count all load cycles including the mean and amplitude value pairs.

In this paper, the mixture distribution model was adopted to analyze the multimodality of load cycles. By comparing the goodness-of-fit and Bayes information criterion (BIC), the type and number of subdistribution were determined. Then, the parameters of subdistribution were estimated using the maximum likelihood estimation method. Meanwhile, the collected variable amplitude loads were extrapolated to the full life of vehicle to completely reflect the stress situation. The joint probability density of mean and amplitude value is shown in Figure 3.

The two-dimensional load spectrum is composed of the load frequencies in the mean and amplitude ranges. According to the load cycles and joint probability density, the load frequency at each load level can be calculated as follows:

$$
n_{i j}=N_{c} \int_{l_{i-1}}^{l_{i}}\left(\int_{l_{j-1}}^{l_{j}} f(x, y) \mathrm{d} y\right) \mathrm{d} x,
$$

where $n_{i j}$ is load frequency, $N_{c}$ is total load frequency, $f(x, y)$ is joint probability density, and $l_{i}, l_{j}, l_{i-1}$, and $l_{j-1}$ are upper and lower bound of amplitude and mean range at the load level $i$ and $j$.

Finally, the two-dimensional load spectrum can be obtained in Table 1.

\section{Stress Analysis Half-Shaft}

In the half-shaft assembly of vehicle, the minor axis on the inside and outside and the major axis are connected by the constant velocity joint, respectively. The critical location of fatigue failure can be determined by calculating the stress of the half-shaft assembly by FEM or analytically. Since the half-shaft under investigation here is shaped in a regular form, we can give the analytical local stress tensor corresponding to the external load as follows. All the location $\left(x^{*}, y^{*}, z^{*}\right)$ is given in the static coordinate system which originates at the wheel center, and its direction aligns with the measured wheel force aforementioned.

3.1. Stress under Bending. The bending moment is the resultant moment of pure bending moment $T_{x}, F_{z}$ and the shear force $T_{z}, F_{x}$. The local bending moment can be thus determined as

$$
M_{x}=T_{x}+F_{z} \cdot y^{*}
$$

where $l_{y}$ is the distance from the infinitesimal to the point of application of external forces.

The local normal and shear stress can then be calculated as equations (3) and (4), respectively:

$$
\sigma_{y y}=\frac{-M_{z} \cdot x^{*}}{I_{z}}
$$

where the second area moment $I_{z}=I_{x}=\left(\pi d^{4} / 64\right)$, and

$$
\sigma_{x y}=\frac{F_{z} \cdot S^{*}}{I_{z} \cdot b}
$$

where $S^{*}$ is the first moment of area below $x^{*}$ and $b$ is the length of the chord at $x^{*}$.

Since the section is circular, similar result in the perpendicular direction could be obtained from $T_{z}$ and $F_{x}$.

3.2. Stress under Tensile/Compression. The tensile or compression stress in the $y$-direction under shaft-axial force $F_{y}$ can be easily computed by the following equation:

$$
\sigma_{y y}=\frac{F_{y}}{I_{x}} .
$$

3.3. Stress under Torsion. For local stress under torsion, the shear stress $\tau_{\rho}$ at which distance to the shaft rotation center is $\rho^{*}$ can be obtained as follows:

$$
\tau_{\rho}=\frac{T_{y} \rho^{*}}{I_{P}},
$$

where the polar moment of inertia $I_{p}$ for circular section is shown as 


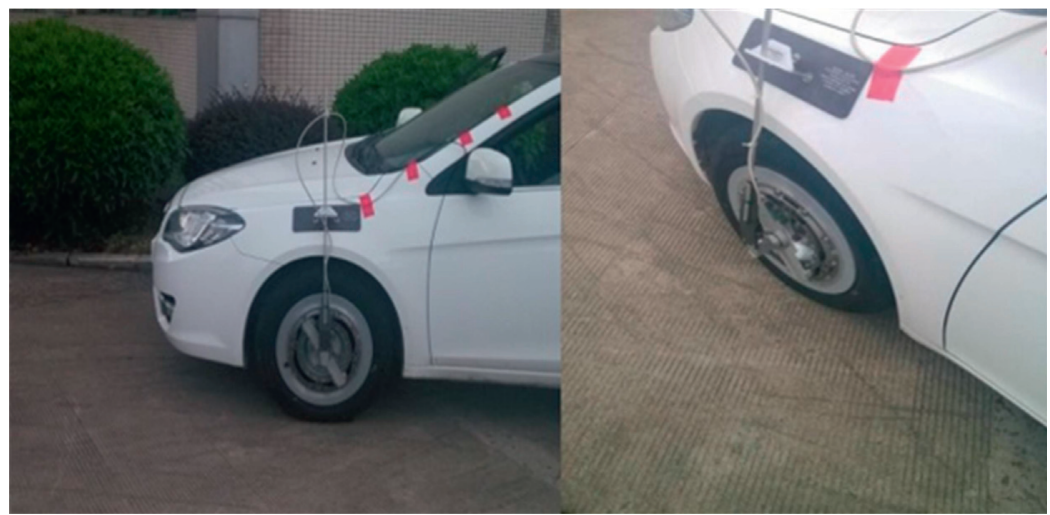

FIGURE 1: Installation of the six-component measuring system.
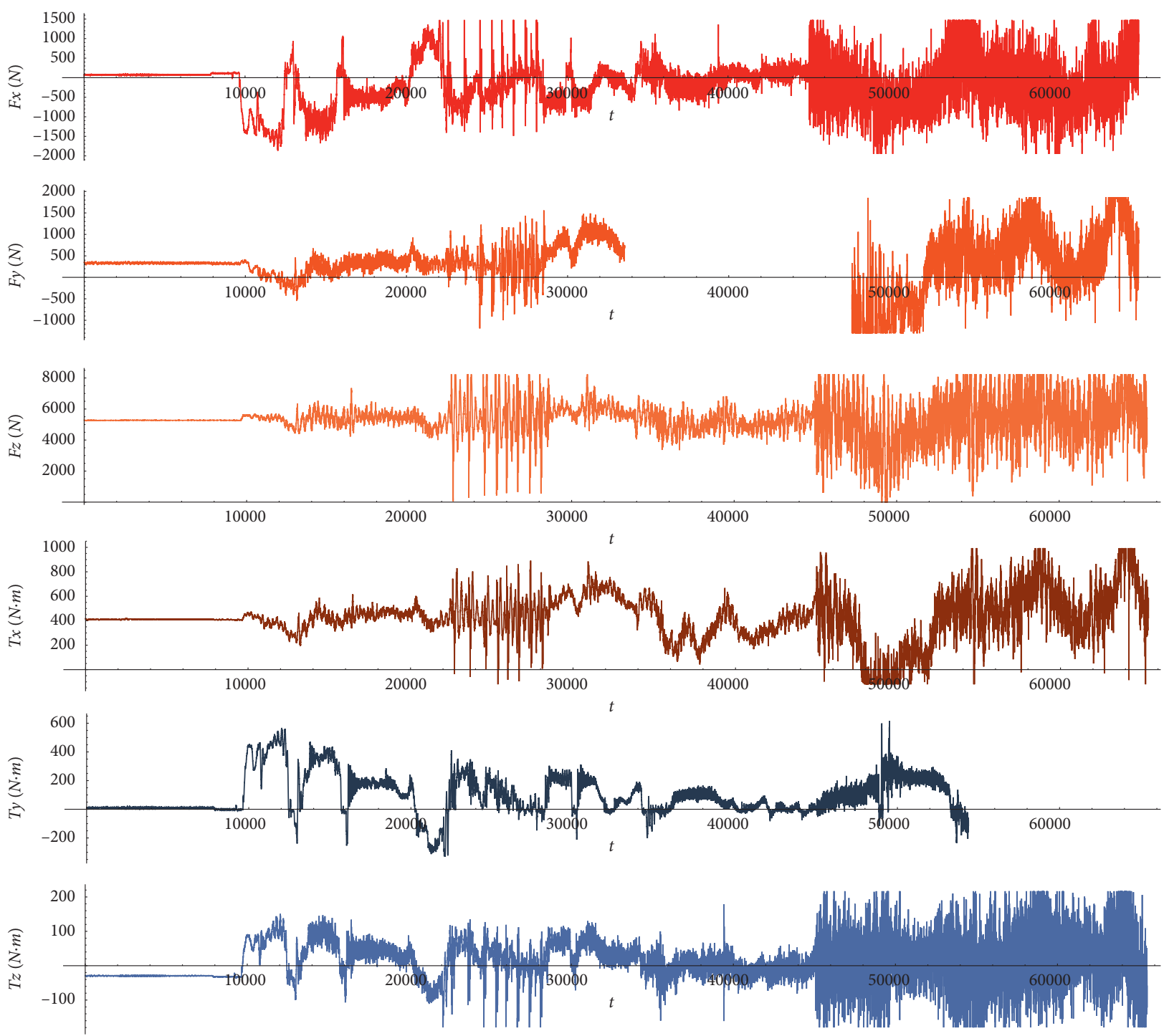

FIgURE 2: The load-time history. 


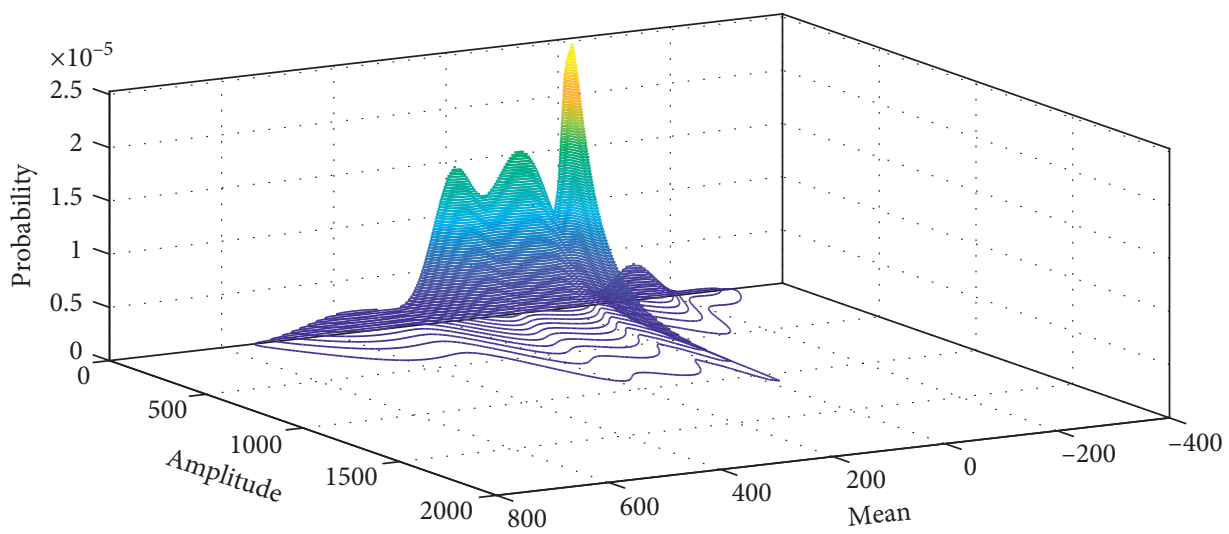

FIgURE 3: The joint probability density of mean and amplitude values.

TABLE 1: The two-dimensional load spectrum.

\begin{tabular}{|c|c|c|c|c|c|c|c|c|c|c|c|c|c|c|c|c|c|}
\hline \multirow{3}{*}{\multicolumn{2}{|c|}{$\begin{array}{l}\text { Mean } \\
(\mathrm{N} \cdot \mathrm{m})\end{array}$}} & \multicolumn{16}{|c|}{ Amplitude $(\mathrm{N} \cdot \mathrm{m})$} \\
\hline & & \multirow{3}{*}{$\begin{array}{l}1 \\
8 \\
0\end{array}$} & \multirow{3}{*}{$\begin{array}{c}2 \\
25 \\
0\end{array}$} & \multirow{3}{*}{$\begin{array}{c}3 \\
51 \\
0\end{array}$} & \multirow{3}{*}{$\begin{array}{c}4 \\
88 \\
0\end{array}$} & \multirow{3}{*}{$\begin{array}{c}5 \\
135 \\
0\end{array}$} & \multirow{3}{*}{$\begin{array}{c}6 \\
191 \\
0\end{array}$} & \multirow{3}{*}{$\begin{array}{c}7 \\
258 \\
0\end{array}$} & \multirow{3}{*}{$\begin{array}{c}8 \\
335 \\
0\end{array}$} & \multirow{3}{*}{$\begin{array}{c}9 \\
422 \\
0\end{array}$} & \multirow{3}{*}{$\begin{array}{c}10 \\
519 \\
0\end{array}$} & \multirow{3}{*}{$\begin{array}{c}11 \\
624 \\
0\end{array}$} & \multirow{3}{*}{$\begin{array}{c}12 \\
737 \\
0\end{array}$} & \multirow{3}{*}{$\begin{array}{c}13 \\
854 \\
0\end{array}$} & \multirow{3}{*}{$\begin{array}{c}14 \\
974 \\
0\end{array}$} & \multirow{3}{*}{$\begin{array}{c}15 \\
1101 \\
0\end{array}$} & \multirow{3}{*}{$\begin{array}{c}16 \\
1234 \\
0\end{array}$} \\
\hline & & & & & & & & & & & & & & & & & \\
\hline 1 & -543 & & & & & & & & & & & & & & & & \\
\hline 2 & -455 & 0 & 0 & 0 & 0 & 0 & 0 & 0 & 0 & 0 & 0 & 0 & 0 & 0 & 0 & 0 & 0 \\
\hline 3 & -368 & 1 & 0 & 0 & 0 & 0 & 0 & 0 & 0 & 0 & 0 & 0 & 0 & 0 & 0 & 0 & 0 \\
\hline 4 & -280 & 34 & 4 & 1 & 0 & 0 & 0 & 0 & 0 & 0 & 0 & 0 & 0 & 0 & 0 & 0 & 0 \\
\hline 5 & -193 & 91 & 11 & 2 & 1 & 0 & 0 & 0 & 0 & 0 & 0 & 0 & 0 & 0 & 0 & 0 & 0 \\
\hline 6 & -105 & 320 & 40 & 10 & 3 & 1 & 0 & 0 & 0 & 0 & 0 & 0 & 0 & 0 & 0 & 0 & 0 \\
\hline 7 & -18 & 998 & 126 & 31 & 11 & 4 & 2 & 1 & 0 & 0 & 0 & 0 & 0 & 0 & 0 & 0 & 0 \\
\hline 8 & 69 & 1403 & 177 & 44 & 15 & 6 & 3 & 2 & 1 & 1 & 1 & 1 & 0 & 0 & 1 & 0 & 0 \\
\hline 9 & 157 & 1386 & 175 & 43 & 15 & 6 & 3 & 1 & 1 & 1 & 0 & 0 & 1 & 0 & 0 & 0 & 0 \\
\hline 10 & 245 & 1038 & 131 & 32 & 11 & 5 & 2 & 1 & 0 & 0 & 0 & 0 & 0 & 0 & 0 & 0 & 0 \\
\hline 11 & 332 & 244 & 30 & 7 & 2 & 1 & 0 & 0 & 0 & 0 & 0 & 0 & 0 & 0 & 0 & 0 & 0 \\
\hline 12 & 420 & 233 & 29 & 7 & 2 & 1 & 0 & 0 & 0 & 0 & 0 & 0 & 0 & 0 & 0 & 0 & 0 \\
\hline 13 & 508 & 102 & 12 & 3 & 1 & 0 & 0 & 0 & 0 & 0 & 0 & 0 & 0 & 0 & 0 & 0 & 0 \\
\hline 14 & 595 & 15 & 1 & 0 & 0 & 0 & 0 & 0 & 0 & 0 & 0 & 0 & 0 & 0 & 0 & 0 & 0 \\
\hline 15 & 683 & 0 & 0 & 0 & 0 & 0 & 0 & 0 & 0 & 0 & 0 & 0 & 0 & 0 & 0 & 0 & 0 \\
\hline 16 & 771 & 0 & 0 & 0 & 0 & 0 & 0 & 0 & 0 & 0 & 0 & 0 & 0 & 0 & 0 & 0 & 0 \\
\hline
\end{tabular}

$$
I_{p}=\int_{A} \rho^{2} \mathrm{~d} A=\frac{\pi d^{4}}{32}
$$

To be clarified that this shear stress is in the local coordinate system $n l r$ which is tangential to the shaft surface, thus, it is necessary to project it to the system we defined in $x y z$. According to the position angle $\theta^{*}=\arctan \left(x^{*} / z^{*}\right)$, of the infinitesimal, the stress tensor can be transformed as follows:

$$
\sigma_{x y z}=Q \cdot \sigma_{n l r} \cdot Q^{T}
$$

where $Q$ is the transform matrix shown as

$$
Q=\left[\begin{array}{ccc}
\cos \theta^{*} & 0 & -\sin \theta^{*} \\
0 & 1 & 0 \\
\sin \theta^{*} & 0 & \cos \theta^{*}
\end{array}\right]
$$

The second column represents the transition in y-axial remains 1 since the $y$-direction in $x y z$ is aligned with the $\mathrm{n}$-direction in $n l r$. Thus, for planar shear stress $\tau_{r l}$ to be projected, we can rewrite equation (8) by the component of local shear stress as

$$
\sigma_{x z}=\left[\begin{array}{cc}
\sin 2 \theta^{*} \tau_{r l} & \cos 2 \theta^{*} \tau_{r l} \\
-\cos 2 \theta^{*} \tau_{r l} & -\sin 2 \theta^{*} \tau_{r l}
\end{array}\right] .
$$

3.4. Resultant Local Stress. The resultant stress is the linear combination of the stress under each independent channel of forces, shown in equation (11) and Table 2:

$$
\sigma_{x y z}=\left[\begin{array}{ccc}
\frac{\sin 2 \theta^{*} T_{y} \rho^{*}}{I_{P}} & \frac{F_{z} \cdot S^{*}}{I_{z} \cdot b_{z}} & \frac{\cos 2 \theta^{*} T_{y} \rho^{*}}{I_{P}} \\
-\frac{F_{z} \cdot S^{*}}{I_{z} \cdot b_{z}} & \frac{F_{y}}{I_{x}}-\frac{M_{z} x^{*}}{I_{z}} & \frac{F_{x} \cdot S^{*}}{I_{x} \cdot b_{x}} \\
-\frac{\cos 2 \theta^{*} T_{y} \rho^{*}}{I_{P}} & -\frac{F_{x} \cdot S^{*}}{I_{x} \cdot b_{x}} & -\frac{\sin 2 \theta^{*} T_{y} \rho^{*}}{I_{P}}
\end{array}\right] .
$$


TABLE 2: Half-shaft local stress components under propagation of the external load.

\begin{tabular}{|c|c|c|c|c|c|c|c|}
\hline External load channel & Type & $\sigma_{x x}$ & $\sigma_{y y}$ & $\sigma_{z z}$ & $\sigma_{y z}$ & $\sigma_{x z}$ & $\sigma_{x y}$ \\
\hline$F_{y}$ & Tensile/compression & & $*$ & & & & \\
\hline$T_{y}^{y}$ & Torsion & * & & * & & * & \\
\hline$F_{x} T_{z}$ & Bending & & $*$ & & & & * \\
\hline$F_{z} T_{x}$ & Bending & & $*$ & & $*$ & & \\
\hline
\end{tabular}

For example, the stress corresponding to the position angle $\theta$ at time $=2 \mathrm{~s}$ and time $=20 \mathrm{~s}$ is shown in Figure 4. The local stress pattern changes as the result of change in external forces. Figure 4(a) shows at time $=2 \mathrm{~s}$ that the local stress is dominated by the normal stress caused by the bending moment, while Figure 4(b) shows at time $=20 \mathrm{~s}$ that the local stress is dominated by the shear stress caused by the torsion moment.

The major axis of half-shaft is shown in Figure 5, and the section radius of each part is shown in Table 3 .

\section{The Fatigue Damage Parameter under Multiaxial Load}

Wang and Brown provided a plausible way of mapping the multiaxial nonproportional stress to fit to any rainflow-like cycle counting methods which are initially targeting to solve uniaxial fatigue load counting. In this paper, the general framework of Wang and Brown's method is adopted while the rainflow counting is taken in replace of the original method and the load event result of which can still be interpreted by the fatigue damage parameter [20].

\subsection{Major Turning Point Identification and Cycle Counting.} Since cyclic deformation is the essential force of failure, it is important to take the strain hardening phenomenon into account. Thus, a rational multiaxial cycle counting method is needed. The von Mises criterion is considered as a good parameter of defining the trend of local stress regarding the local energy gaining or losing.

The equivalent von Mises stress is shown as follows:

$$
\sigma_{e}=\frac{1}{\sqrt{2}\left(1+\nu^{\prime}\right)} \sqrt{\left(\varepsilon_{x}-\varepsilon_{y}\right)^{2}+\left(\varepsilon_{y}-\varepsilon_{z}\right)^{2}+\left(\varepsilon_{z}-\varepsilon_{x}\right)^{2}+\left(\gamma_{x y}^{2}+\gamma_{y z}^{2}+\gamma_{z x}^{2}\right)},
$$

where the local strains $\varepsilon_{x}, \varepsilon_{y}, \varepsilon_{z}, \gamma_{x y}^{2}, \gamma_{y z}^{2}$, and $\gamma_{z x}^{2}$ can be calculated from local stresses.

The rainflow cycle counting method is then taken on to the new equivalent strain history. In this paper, standard workflow of rainflow cycle counting is followed. The detailed step and algorithm could be found in [15].

The result of rainflow counting is shown as a list, and the start time is ordered in time, but the end time is not since the time duration of the rainflow counting load cycle event has no constant interval.

4.2. The Fatigue Damage Parameter. In uniaxial fatigue damage, the mean and amplitude of the cycle are needed to evaluate the fatigue damage. The equivalent von Mises stress is only used as the indicator to identify the loading and unloading process at each infinitesimal for rainflow cycle counting. According to the critical plane approach, the actual fatigue damage components are the local shear stress and its corresponding normal stress, which could be extract from the original local stress tensor within the time section of each load event, other than using the mean and amplitude of equivalent von Mises stress to evaluate the fatigue damage parameter. Also when the time sections coincide with each other, the desired stress is taken only once where the actual loading and unloading event happened. The critical plane is assumed to be perpendicular to the surface in the following computation $[12,33]$.

Therefore, the fatigue damage of each load cycle event is evaluated by the following equations:

$$
\frac{\Delta \varepsilon}{2} \sigma_{\max }=\left(\frac{\sigma_{f}^{\prime 2}}{E}\right)\left(2 N_{f}\right)^{2 b}+\sigma^{\prime} \varepsilon_{f}^{\prime}\left(2 N_{f}\right)^{b+c},
$$

where $\Delta \varepsilon$ is the strain range in each load event, $\sigma_{\max }$ is the maximum normal stress in the same event, $N_{f}$ is the number of stress cycles, $\sigma_{f}^{\prime}$ is fatigue strength coefficient, $\varepsilon_{f}^{\prime}$ is the fatigue ductility coefficient, $b$ is fatigue strength exponent, $c$ is the fatigue ductility exponent, and $E$ is tensile elastic modulus, and

$$
\frac{\Delta \gamma}{2}\left(1+\frac{\sigma_{n, \max }}{\sigma_{y}}\right)=\left(\frac{\tau_{f}^{* 2}}{G}\right)\left(2 N_{f}\right)^{b}+\gamma_{f}^{*}\left(2 N_{f}\right)^{c},
$$

where $\Delta \gamma$ is the maximum shear strain range and $\sigma_{n \text {, max }}$ is the maximum normal stress on the maximum shear plane. All the stress or strain in each cycle can be thus extracted from the rainflow cycle counting result.

Infinitesimal located on the surface of different radius at each section in Table 3 was computed for searching the predicted fracture point.

The 40Cr steel, or 5140 in AISI, is a kind of commonly used half-shaft material, and its fatigue performance parameters are shown in Table 4 [34]. The detailed specs of this material could be found in [34]. The same of the properties of other steel could be found in [35].

4.3. Fatigue Life Prediction of Half-Shaft. The complicated working condition causes the fatigue fracture of the halfshaft after the continuous impact of the road load. Therefore, predicting effectively the fatigue life of half-shaft and improving the quality are necessary for the reliability. In this paper, the linear fatigue cumulative damage theory, as the Miner rule, is adopted to predict the fatigue life of half-shaft. The Miner rule assumes that the fatigue damage caused by 


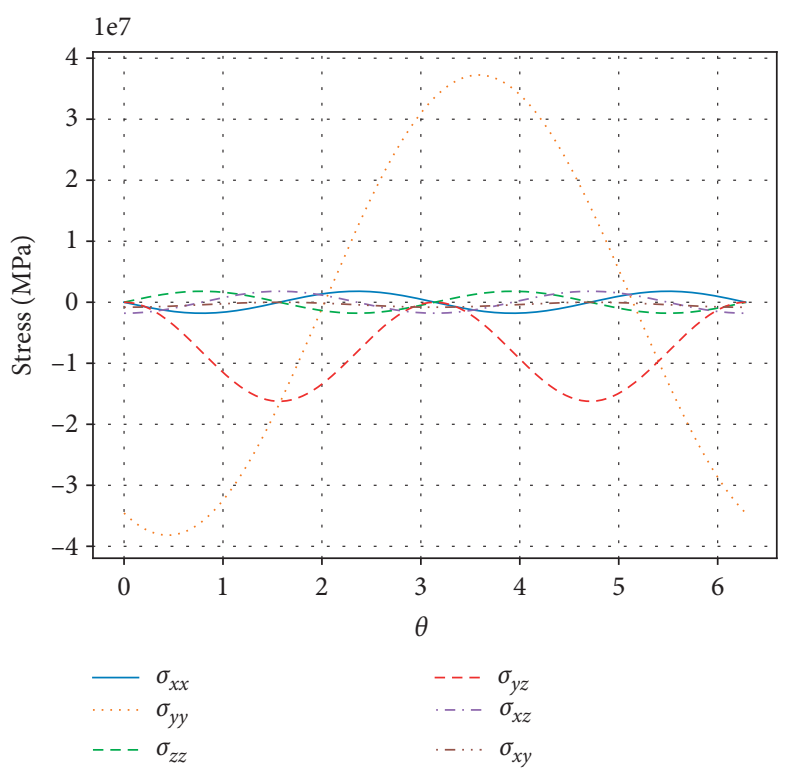

(a)

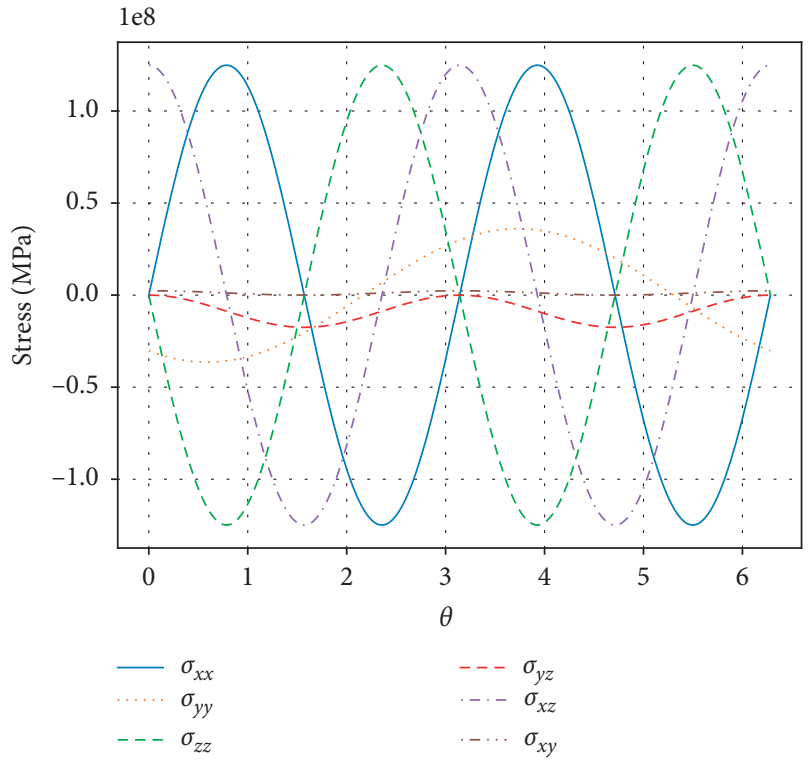

(b)

FIgURE 4: The stress associated with different position angle $\theta$. (a) At time $=2 \mathrm{~s}$ and (b) at time $=20 \mathrm{~s}$.

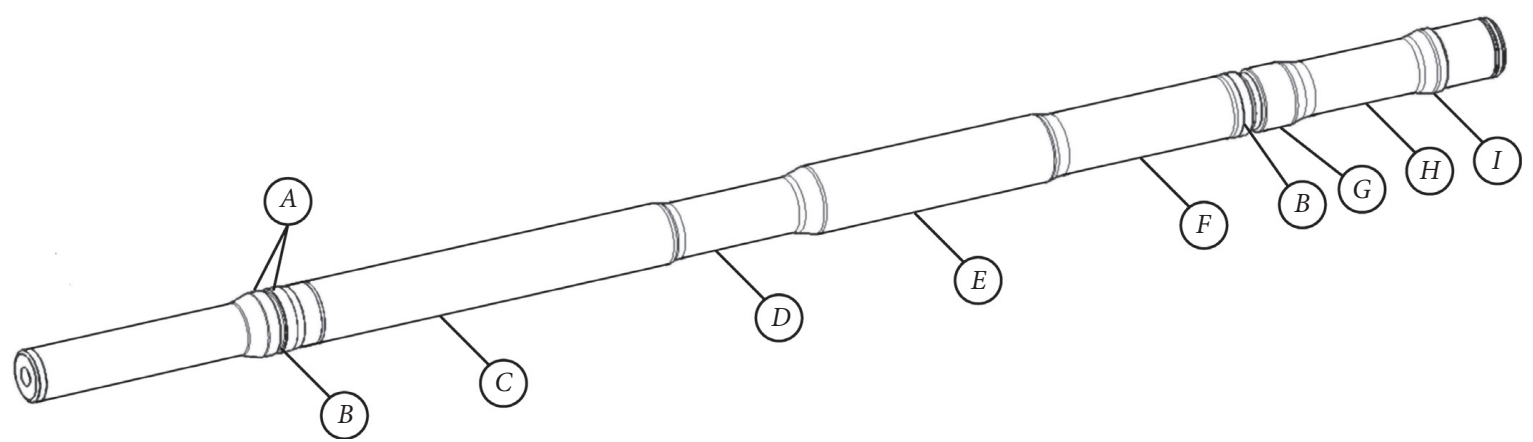

FIgURE 5: The major axis of half-shaft.

TABLE 3: The radius by each section of the half-shaft.

\begin{tabular}{lc}
\hline Number & Radius $(\mathrm{mm})$ \\
\hline$A$ & 13.5 \\
$B$ & 12 \\
$C$ & 13 \\
$D$ & 11.75 \\
$E$ & 14.3 \\
$F$ & 13 \\
$G$ & 13.3 \\
$H$ & 11.5 \\
$I$ & 13.35 \\
\hline
\end{tabular}

TABLE 4: The fatigue performance parameters of $40 \mathrm{Cr}$ steel.

\begin{tabular}{lllll}
\hline$\sigma_{f}^{\prime}(\mathrm{MPa})$ & $\varepsilon_{f}^{\prime}$ & $b$ & $C$ & $E(\mathrm{MPa})$ \\
\hline 1544.91 & 1.5106 & -0.0796 & -0.7123 & 218000 \\
\hline
\end{tabular}

each load cycle is independent and can be superposed linearly. The fatigue failure occurs when the cumulative fatigue damage is 1 . Therefore, the cumulative fatigue damage parameter $D$ and the fatigue life $T$ can be calculated as follows:

$$
\begin{aligned}
& D=\sum_{i=1}^{n} \frac{1}{2 N_{f, i}}, \\
& T=\frac{1}{D^{\prime}},
\end{aligned}
$$

where $D$ is the fatigue damage parameter associated with each load event, $N_{f, i}$ is the number of load cycles until failure of the ith load event, and $T$ is the number of full blocks of damage until the part fails.

At last, the accumulative fatigue damage parameter of the multiaxial random load in a single load block is $1.94 \times$ $10^{-6}$ and every load block lasts for $127 \mathrm{~s}$. According to equation (16), the fatigue life can be calculated as 15,463 hours at the weakest point in the half-shaft assembly. The result exceeds the service life of noncommercial vehicles and meets the safety requirement of transmission parts. 


\section{Conclusions}

This paper mainly analyzes the fatigue life prediction of halfshaft under the multiaxial random load based on Wang and Brown's method. The von Mises equivalent stress is generated for rainflow cycle counting. The fatigue damage parameter of each individual load event is than computed. The linear accumulative rule is used to predict the fatigue life of the half-shaft. The main highlight is summarized as follows:

(1) The load spectrum of the half-shaft under the multiaxial random load in working condition is compiled, which provides the basis for the benchmark test is applied as the external excitation instead of originated load history in the fatigue life prediction.

(2) The stress analysis of half-shaft is carried out analytically. Any stress tensor within the geometry of half-shaft could be computed from the resultant of bending, torsion, and tensile forces and moments.

\section{Nomenclature}

$B$ : $\quad$ Fatigue strength exponent

C: $\quad$ Fatigue ductility exponent

$D$ : Cumulative fatigue damage

E: Tensile elastic modulus

$G$ : $\quad$ Shear elastic modulus

$I_{p}$ : $\quad$ Polar moment of inertia

$N_{f}$ : The number of stress cycles

$N_{f, i}$ : The number of load cycles until failure

$R: \quad$ Radius of half-shaft section

$T: \quad$ Fatigue life

$\Delta \varepsilon: \quad$ Cycle strain

$\varepsilon_{a}: \quad$ Strain amplitude

$\varepsilon_{f}^{\prime}: \quad$ Fatigue ductility coefficient

$\rho: \quad$ Radius

$\sigma_{e}: \quad$ von Mises equivalent stress

$\sigma_{f}^{\prime}$ : Fatigue strength coefficient

$\sigma_{m}:$ Mean stress

$\tau_{\max }:$ Shear stress at the section edge $\rho=R$

$\tau_{p}: \quad$ Shear stress

$\theta: \quad$ Rotation angle.

\section{Data Availability}

Data sharing is not applicable to this article as no new data were created or analyzed in this study.

\section{Conflicts of Interest}

The authors have no conflicts of interest relevant to this article.

\section{Acknowledgments}

This work was supported by the National Natural Science Foundation of China (51675324).

\section{References}

[1] R. I. Stephens, A. Fatemi, R. R. Stephens, and H. O. Fuchs, Metal Fatigue in Engineering, John Wiley \& Sons, Hoboken, NY, USA, 2000.

[2] X. Liu, F. Kan, H. Wang, X. Xin, Z. Wang, and H. Huang, "Fatigue life prediction of clutch sleeve based on abrasion mathematical model in service period," Fatigue \& Fracture of Engineering Materials \& Structures, vol. 43, no. 3, pp. 488-501, 2020.

[3] M. Wang, X. Liu, X. Wang, and Y. Wang, "Probabilistic modeling of unified S-N curves for mechanical parts," International Journal of Damage Mechanics, vol. 27, no. 7, pp. 979-999, 2018.

[4] G. Qian, Y. Li, D. S. Paolino, A. Tridello, F. Berto, and Y. Hong, "Very-high-cycle fatigue behavior of Ti-6Al-4V manufactured by selective laser melting: effect of build orientation," International Journal of Fatigue, vol. 136, Article ID 105628, 2020.

[5] G. Qian, Z. Jian, Y. Qian, X. Pan, X. Ma, and Y. Hong, "Veryhigh-cycle fatigue behavior of AlSi10Mg manufactured by selective laser melting: effect of build orientation and mean stress," International Journal of Fatigue, vol. 138, Article ID 105696, 2020.

[6] G. Qian, Z. Jian, X. Pan, and F. Berto, "In-situ investigation on fatigue behaviors of Ti-6Al-4V manufactured by selective laser melting," International Journal of Fatigue, vol. 133, Article ID 105424, 2020.

[7] S. A. Mutasher, B. B. Sahari, A. M. S. Hamouda, and S. M. Sapuan, "Experimental study of bending fatigue characteristics of a hybrid aluminum/composite drive shaft," Journal of Composite Materials, vol. 41, no. 18, pp. 2267-2288, 2007.

[8] J. Wertz, M. H. Shen, O. Scott-Emuakpor, T. George, and C. Cross, "An energy-based torsional-shear fatigue lifing method," Experimental Mechanics, vol. 52, no. 7, pp. 705-715, 2012.

[9] J.-M. Shin, D.-S. Han, K.-H. Lee, and S.-H. Han, "Using stress relief grooves to reduce stress concentration on axle drive shaft," Journal of Mechanical Science and Technology, vol. 28, no. 6, pp. 2121-2127, 2014

[10] D.-G. Lee, K.-C. Jang, J.-M. Kuk, and I.-S. Kim, "Comparison of the fatigue life of FF shaft material according to various environmental temperatures," The International Journal of Advanced Manufacturing Technology, vol. 26, no. 7-8, pp. 896-908, 2005.

[11] M. Banuta and I. Tarquini, "Fatigue failure of a drive shaft," Journal of Failure Analysis and Prevention, vol. 12, no. 2, pp. 139-144, 2012.

[12] A. Fatemi and N. Shamsaei, "Multiaxial fatigue: an overview and some approximation models for life estimation," International Journal of Fatigue, vol. 33, no. 8, pp. 948-958, 2011.

[13] H. Wang, X. Liu, M. Zhang, Y. Wang, and X. Wang, "Prediction of material fatigue parameters for low alloy forged steels considering error circle," International Journal of Fatigue, vol. 121, pp. 135-145, 2019.

[14] H. Ge, X. Liu, Y. Fang, H. Wang, X. Wang, and M. Zhang, "An improved bootstrap method introducing error ellipse for numerical analysis of fatigue life parameters," Engineering Computations, 2020.

[15] G. Marsh, C. Wignall, P. R. Thies et al., "Review and application of Rainflow residue processing techniques for accurate fatigue damage estimation," International Journal of Fatigue, vol. 82, pp. 757-765, 2016. 
[16] J. A. Bannantine, "A variable amplitude multiaxial fatigue life prediction model," in Fatigue under Biaxial and Multiaxial Loading, K. Kussmaul, D. McDiarmid, and D. Socie, Eds., pp. 35-51, London: European Structural Integrity Society, ESIS Publication 10, Mechanical Engineering Publications, London, UK, 1991.

[17] H. Wang, X. Liu, X. Wang, and Y. Wang, "Numerical method for estimating fatigue crack initiation size using elastic-plastic fracture mechanics method," Applied Mathematical Modelling, vol. 73, pp. 365-377, 2019.

[18] C. Li, Q. Sun, Y. Yang, J. Li, G. Zhang, and Z. Zhang, "Theoretical estimation of fatigue crack initiation life for metallic materials," Journal of Materials Engineering and Performance, vol. 22, no. 3, pp. 655-663, 2013.

[19] Z. You, X. Liu, X. Wang, Y. Wang, and X. Wang, "Numerical method for fatigue life of aircraft lugs under thermal stress," Journal of Aircraft, vol. 57, no. 4, pp. 597-602, 2020.

[20] C. H. Wang and M. W. Brown, "Life prediction techniques for variable amplitude multiaxial fatigue-part 1: theories," 1996.

[21] B.-R. You and S.-B. Lee, "A critical review on multiaxial fatigue assessments of metals," International Journal of $\mathrm{Fa}$ tigue, vol. 18, no. 4, pp. 235-244, 1996.

[22] Y. Wang and L. Susmel, "The Modified Manson-Coffin Curve Method to estimate fatigue lifetime under complex constant and variable amplitude multiaxial fatigue loading," International Journal of Fatigue, vol. 83, pp. 135-149, 2016.

[23] X. Pitoiset, I. Rychlik, and A. Preumont, "Spectral methods to estimate local multiaxial fatigue failure for structures undergoing random vibrations," Fatigue \& Fracture of Engineering Materials \& Structures, vol. 24, no. 11, pp. 715-727, 2001.

[24] A. Ince and G. Glinka, "A generalized fatigue damage parameter for multiaxial fatigue life prediction under proportional and non-proportional loadings," International Journal of Fatigue, vol. 62, pp. 34-41, 2014.

[25] C. H. Wang and M. W. Brown, "A path-independent parameter for fatigue under proportional and non-proportional loading," Fatigue \& Fracture of Engineering Materials \& Structures, vol. 16, no. 12, pp. 1285-1297, 1993.

[26] J. J. Xiong and R. A. Shenoi, Fatigue and Fracture Reliability Engineering, Springer Science \& Business Media, Berlin, Germany, 2011.

[27] X. Liu, M. Zhang, H. Wang, J. Luo, J. Tong, and X. Wang, "Fatigue life analysis of automotive key parts based on improved peak-over-threshold method," Fatigue \& Fracture of Engineering Materials \& Structures, vol. 43, no. 8, pp. 18241836, 2020.

[28] H. Chen, Y. Sun, and K. Wu, "Load spectrum testing and analysis for transmission system of closed high-speed press," Procedia Engineering, vol. 81, pp. 1645-1650, 2014.

[29] S. Geng, X. Liu, X. Yang, Z. Meng, X. Wang, and Y. Wang, "Load spectrum for automotive wheels hub based on mixed probability distribution model," Proceedings of the Institution of Mechanical Engineers, Part D: Journal of Automobile Engineering, vol. 233, no. 14, pp. 3707-3720, 2019.

[30] P. Heuler and H. Klätschke, "Generation and use of standardised load spectra and load-time histories," International Journal of Fatigue, vol. 27, no. 8, pp. 974-990, 2005.

[31] J. Tong, X. Liu, M. Wang, Y. Wang, and X. Wang, "Research on random load characteristic based on mixture distribution model," Journal of Testing and Evaluation, vol. 47, no. 1, pp. 537-555, 2019.

[32] X. Yang, X. Liu, J. Tong, Y. Wang, and X. Wang, "Research on load spectrum construction of bench test based on automotive proving ground," Journal of Testing and Evaluation, vol. 46, no. 1, pp. 244-251, 2018.

[33] C. C. Chu, "Fatigue damage calculation using the critical plane approach," Journal of Engineering Materials and Technology, vol. 117, no. 1, pp. 41-49, 1995.

[34] Z. D. Wang, "Research on the low-cycle fatigue experiment of 40 Cr steel," Mechanical Strength, vol. 4, pp. 64-66, 1988.

[35] H.-S. L.-A. Steels, "ASM handbook, volume 1, properties and selection: irons, steels, and high performance alloys section: carbon and low-alloy steels," 2005. 